\title{
A NOTE ON CERTAIN SUBCLASS OF CLOSE-TO-CONVEX FUNCTIONS
}

\author{
SHIGEYOSHI OWA \\ Department of Mathematics \\ Kinki University \\ Higashi-Osaka, Osaka 577, Japan \\ LIU LIQUAN \\ Department of Mathematics \\ Heilongjiang University \\ Harbin, China \\ WANCANG MA \\ Department of Mathematics \\ Northwest University \\ Xian, China
}

(Received June 25, 1987 and in revised form July 31, 1987)

ABSTRACT. The object of the present paper is to show a result for functions belonging to class $P^{\prime}(1-\alpha, 0)$ which is a subclass of close-to-convex functions in the unit disk $U$.

KEY WORDS AND PHRASES. Close-to-Convex of order $\alpha$, Class $P^{\prime}(\alpha)$, Class $P^{\prime}(1-\alpha, 0)$, subordination.

1980 AMS SUBJECT CLASSIFICATION CODE. $30 \mathrm{C} 45$.

\section{INTRODUCTION}

Let $A$ denote the class of functions of the form

$$
f(z)=z+\sum_{n=2}^{\infty} a_{n} z^{n}
$$

which are analytic in the unit disk $U=\{z:|z|<1\}$. A function $f(z)$ belonging to $A$ is said to be in the class $P^{\prime}(\alpha)$ (according to Goodman [4]) if and only if it satisfies the condition

$$
\operatorname{Re}\left\{f^{\prime}(z)\right\}>\alpha
$$

for some $\alpha(0 \leq \alpha<1)$ and for all z $\varepsilon U$. Note that $P^{\prime}(\alpha)$ the subclass of close-toconvex functions of order $\alpha$ in the unit disk $U$. Further, let $P^{\prime}(1-\alpha, 0)$ (according to Goodman [4]) be the subclass of A consisting of all functions which satisfy the condition

$$
\left|f^{\prime}(z)-1\right|<1-\alpha
$$

for some $\alpha(0 \leqq \alpha<1)$ and for all z $\varepsilon U$. 
It is clear that $P^{\prime}(1-\alpha, 0)$ is the subclass of $P^{\prime}(\alpha)$ for $0 \leq \alpha<1$. Nunokawa, Fukui, Owa, Saitoh and Sekine [1] showed that functions in $P^{\prime}(1-\alpha, 0)$ are starlike in $|z|<r_{1}$, where $r_{1}$ is the root of the equation

$$
\log \left\{\frac{1-(2 /(3-\alpha))^{2}\left(r-(1-x) r^{2} / 2\right)^{2}}{1-r^{2}}\right\}+\sin ^{-1}((1-\alpha) r)=\pi \text {. }
$$

Also, Fukui, Owa, Ogawa and Nunokawa [2] proved that functions in $P^{\prime}(\alpha)$ are starlike in $|z|<r_{2}$, where $r_{2}$ is the smallest root in $[0,1)$ of the equation

$$
\sin ^{-1} \frac{2(1-\alpha) r}{1-(2 \alpha-1) r^{2}}+\log \frac{1}{1-r^{2}}=\pi .
$$

For the functions $f(z)$ and $g(z)$ belonging to $A$, we say that $f(z)$ is subordinate to $\mathbf{g}(z)$ in $U$ if there exists an analytic function $w(z)$ in $U$ such that $|w(z)|<1$ for $z^{\prime} \varepsilon U$ and $f(z)=g(w(z))$. We denote by $f(z) \prec g(z)$ this subordination. In particular, if $g(z)$ is univalent in $U$ the subordination $f(z) \prec g(z)$ is equivalent to $f(0)=g(0)$ and $f(U) \subset g(U)(\operatorname{cf} .[3])$.

\section{MAIN RESULT}

In order to prove our main result, we have to recall here the following lemma due to Miller and Mocanu [5].

LEMMA. Let $q(z)$ be an injective mapping of $\bar{U}$ onto $\bar{Q}$, with $q(0)=1$, such that $q(z)$ is regular on $\bar{U}$ except for at most one pole on $\partial U$. Let $p(z)=1+p_{1} z+p_{2} z^{2}+\ldots$ be analytic in $U$ with $p(z) \notin 1$. If there exists a point $z_{0} \varepsilon U$ such that $p\left(z_{0}\right) \varepsilon \partial U$ and $p\left(|z|<\left|z_{0}\right|\right) \subset Q$, then $z_{0} p^{\prime}\left(z_{0}\right)={ }^{2} w_{0} q^{\prime}\left(w_{0}\right)$, where $m \geq 1$ and $w_{0}=e^{i \theta_{0}}=q^{-1}\left(p\left(z_{0}\right)\right)$.

Applying the above lemma, we derive

THEOREM. Let the function $f(z)$ defined by (1) be in the class $P^{\prime}(1-\alpha, 0)$. Then

$$
\frac{f(z)}{z}<1+\frac{(1-\alpha) z}{2} .
$$

PROOF. Let $q(z)=1+(1-\alpha) z / 2$ and $p(z)=f(z) / z$. It is clear that the result holds true if $\mathrm{p}(\mathrm{z}) \equiv 1$ for $z \varepsilon U$.

Assume that $p(z) \not 1$ for $z \varepsilon U$ and the subordination $p(z) \prec q(z)$ does not hold in $U$. Then there exists a point $z_{0} \varepsilon U$ such that $p\left(z_{0}\right) \varepsilon \partial q(U)$ and $p\left(|z|<\left|z_{0}\right|\right) \subset q(U)$. Therefore, applying the lemma, we get

$$
\begin{aligned}
f^{\prime}\left(z_{0}\right) & =z_{0} p^{\prime}\left(z_{0}\right)+p\left(z_{0}\right) \\
& ={ }^{n} w_{0} q^{\prime}\left(w_{0}\right)+q\left(w_{0}\right) \\
& =\frac{m(1-\alpha) w_{0}}{2}+\frac{(1-\alpha) w_{0}}{2}+1 \\
& =1+\frac{(m+1)(1-\alpha) w_{0}}{2},
\end{aligned}
$$


where $m \geq 1$ and $\left|w_{n}\right|=1$. Thus

$$
\left|f^{\prime}\left(z_{0}\right)-1\right|=\frac{(m+1)(1-\alpha)}{2} \geq 1-\alpha,
$$

which contradicts the hypothesis that $f(z) \varepsilon P^{\prime}(1-a, 0)$. So we must have $p(z) \prec q(z)$ in $U$. This completes the proof of Theorem.

Finally, we have

CORALLARY 1. Let the function $f(z)$ defined by $(1.1)$ be in the class $P^{\prime}(1-\alpha, 0)$. Then

$$
\operatorname{Re}\left\{e^{i \beta \frac{f(z)}{z}}\right\}>0
$$

where $|\beta| \leqq \pi / 2-\sin ^{-1}(1-\alpha) / 2$.

CORALLARY 2. Let the function $f(z)$ defined by $(1.1)$ be in the class $P^{\prime}(1-\alpha, 0)$. Then

$$
\operatorname{Re}\left\{\frac{f(z)}{z}\right\}>0
$$

ACKNOWLEDGEMENTS. The authors would like to thank the referee of the paper for his thoughtful encouragement and numerous helpful advices.

\section{REFERENCES}

1. NUNOKAWA, M., FUKUI, S., OWA, S., SAITOH, H. and SEKINE, T., On the Starlike Boundary of Univalent Functions, to appear.

2. FUKUI, S., OWA, S., OGAWA, S. and NUNOKAWA, M., A Note on a Class of Analytic Functions Satisfying $\operatorname{Re}\left\{f^{\prime}(z)\right\}>\alpha$, Bull. Fac. Edu. Wakayama Univ. Nat. Sci. 36 (1987) 13-17.

3. DUREN, P.L., Univalent Functions, Grudleheren der Mathematischen Wissenschaften 259, Springer-Verlag, New York, Berlin, Heidelberg and Tokyo, 1983.

4. GOODMAN, A.W., Univalent Functions. Vo1. II, Mariner Publ. Comp. Inc., 1983.

5. MILLER, S.S. and MOCANU, P.T., Second Order Differential Inequalitiesin the Complex Plane, J. Math. Anal. App1. 65 (1978) 289-305. 


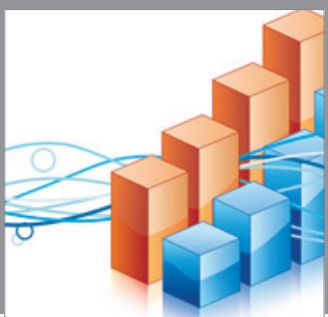

Advances in

Operations Research

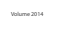

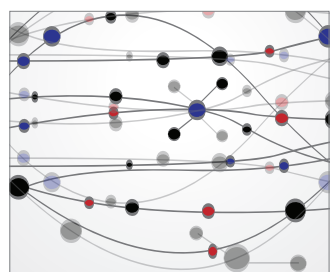

\section{The Scientific} World Journal
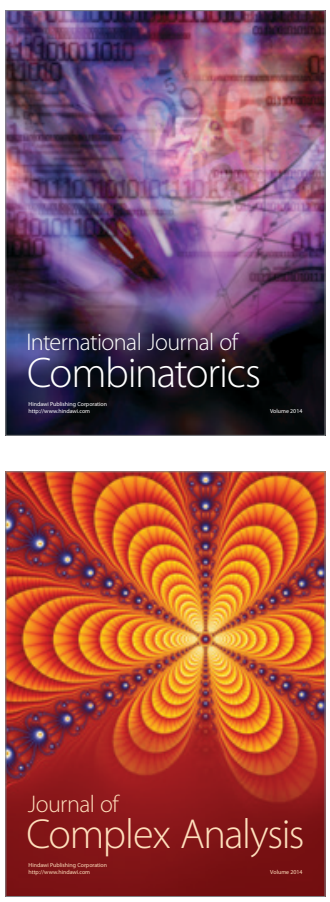

International Journal of

Mathematics and

Mathematical

Sciences
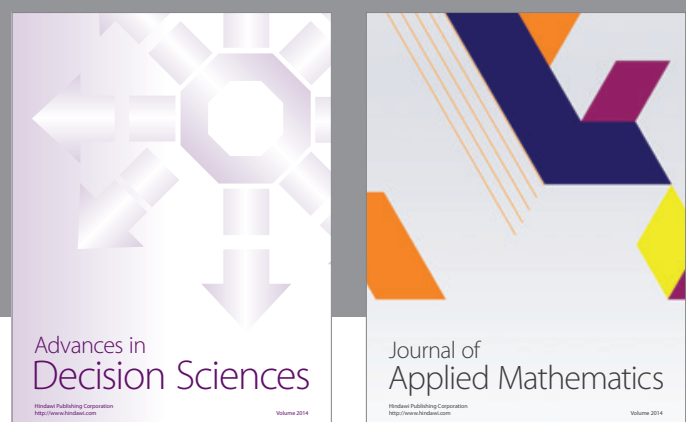

Journal of

Applied Mathematics
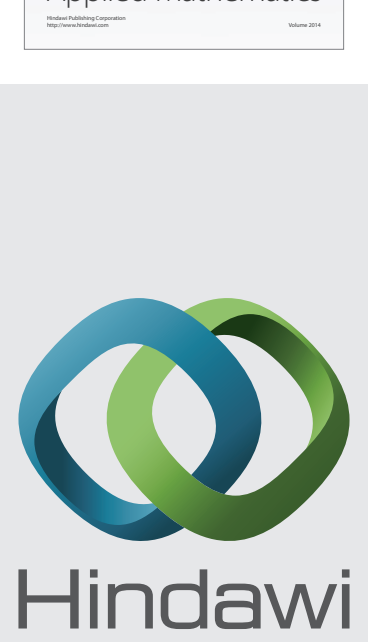

Submit your manuscripts at http://www.hindawi.com
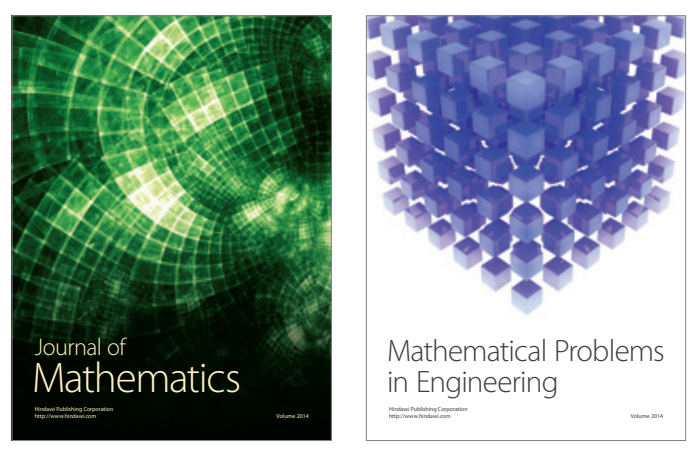

Mathematical Problems in Engineering
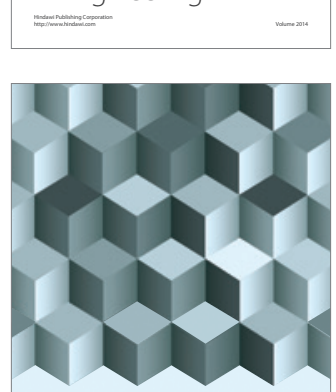

Journal of

Function Spaces
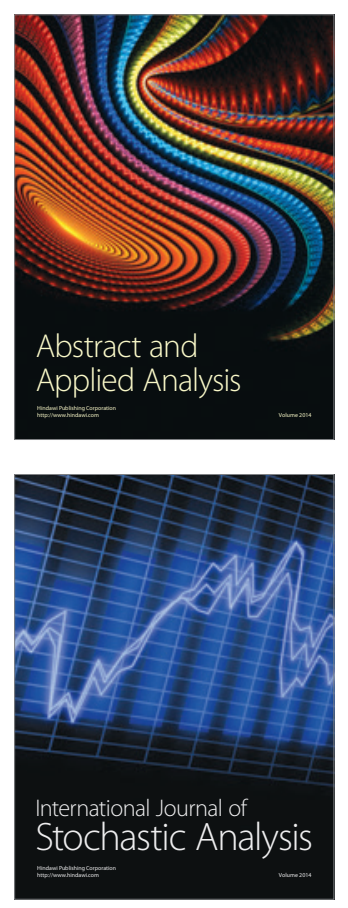

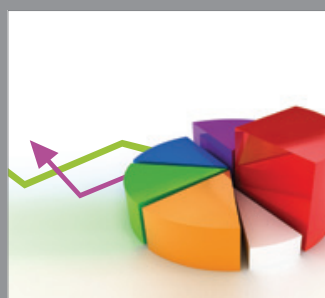

ournal of

Probability and Statistics

Promensencen
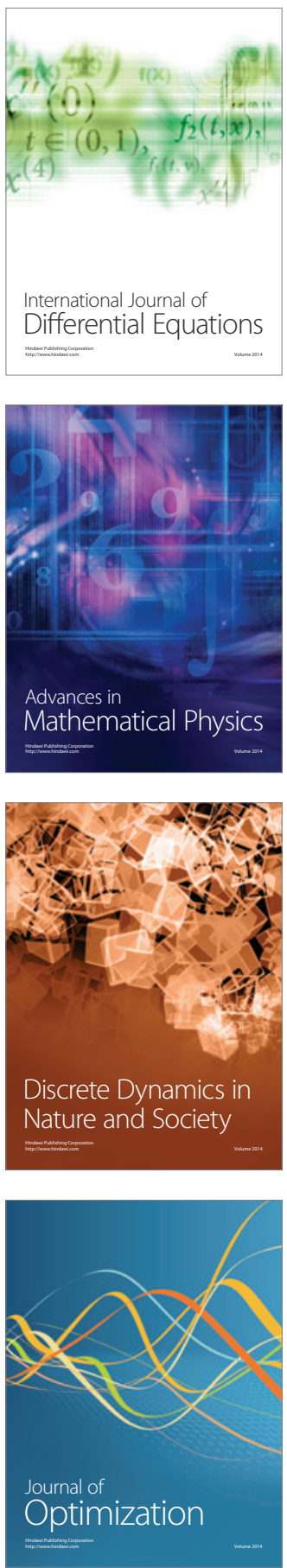